\title{
Article
}

\section{Integration of Sentinel-3 and MODIS vegetation indices with ERA-5 agro-meteorological indicators for operational crop yield forecasting}

\author{
Jędrzej S. Bojanowski 1,+*®D, Sylwia Sikora ${ }^{1,+}$, Jan P. Musiał ${ }^{1} \mathbb{1}$, Edyta Woźniak ${ }^{2} \mathbb{D}$, \\ Katarzyna Dąbrowska-Zielińska ${ }^{1}$ (D), Przemysław Slesiński ${ }^{3}$, Tomasz Milewski ${ }^{3}$ and Artur Łączyński ${ }^{3}$ \\ 1 Remote Sensing Centre, Institute of Geodesy and Cartography, Warsaw, Poland \\ 2 Space Research Centre, Polish Academy of Sciences, Warsaw, Poland \\ 3 Statistics Poland, Warsaw, Poland \\ * Correspondence: jedrzej.bojanowski@gmail.com \\ + These authors contributed equally to this work.
}

\begin{abstract}
Timely crop yield forecasts at national level are substantial to support food policies, to assess agricultural production and to subsidize regions affected by food shortage. This study presents an operational crop yield forecasting system for Poland that employs freely available satellite and agro-meteorological products provided by the Copernicus programme. The crop yield predictors consist of: (1) vegetation condition indicators provided daily by Sentinel-3 OLCI (optical) and SLSTR (thermal) imagery, (2) a backward extension of Sentinel-3 data (before 2018) derived from cross-calibrated MODIS data, (3) air temperature, total precipitation, surface radiation, and soil moisture derived from ERA- 5 climate reanalysis generated by the European Centre for Medium-Range Weather Forecasts. The crop yield forecasting algorithm is based on thermal time (growing degree days derived from ERA-5 data) to better follow the crop development stage. The recursive feature elimination is used to derive an optimal set of predictors for each administrative unit, which are ultimately employed by the Extreme Gradient Boosting regressor to forecast yields using official yield statistics as a reference. According to intensive leave-one-year-out cross validation for 2000-2019 period, the relative RMSE for NUTS- 2 units are: $8 \%$ for winter wheat, and $13 \%$ for winter rapeseed and maize. Respectively, for the LAU units it equals $14 \%$ for winter wheat, $19 \%$ for winter rapeseed, and $27 \%$ for maize. The system is designed to be easily applicable in other regions and to be easily adaptable to cloud computing environments (such as DIAS or Amazon AWS), where data sets from the Copernicus programme are directly accessible.
\end{abstract}

Keywords: satellite data; machine learning; data calibration; thermal time; growing degree days; Extreme Gradient Boosting; crop yield; crop monitoring

\section{Introduction}

Reliable and timely country-wide crop yield forecasts play an important role in supporting national agricultural policies, food security, and planning of food supplies in countries affected by food shortage [1]. Moreover, crop yield data have been increasingly used to analyze agricultural productivity potential [2,3], carbon and nitrogen cycles [4,5], greenhouse gas emissions from agriculture [6], as well as impact of climate change on agricultural production [7]. In this respect, food shortage has become more frequent due to extreme weather events that are more likely to occur under the changing climate [8].

Remotely sensed satellite data sets offer unique, timely, objective, economical and spatially homogeneous information on agriculture over vast areas [9]. Therefore, they have been widely used to monitor crop growth and forecast crop yields (e.g., [9-19]. The comprehensive overview on utilization of satellite data for agriculture monitoring is given by Weiss et al. (2020) [20]. Recently, the Copernicus programme with Sentinel-1 (radar) and Sentinel-2 (optical) satellite constellations has opened a new chapter in 
monitoring agriculture production on a country level. Coupling data from these two instruments featuring frequent revisit (3-6 days depending on latitude) and high spatial resolution (10-20 $\mathrm{m}$ ) has proved to provide accurate crop type maps at a regional level [21-23]. Nevertheless, applicability of Sentinel-2 imagery to forecast crop yields is limited due to short time series ( 5 years to date) and due to lack of consistent crop yield reference data at a field scale across a country.

The most common approach to forecast crop yields using satellite data is to build a statistical model which relates annual crop condition anomalies described by vegetation indices (e.g. NDVI or fAPAR) to national statistics of crop yields [9,11,24-26]. Such approach benefits from long-term multidecadal satellite observations, which are available from low and moderate resolution (250-1000 m) satellite sensors such as AVHRR, VEGETATION or MODIS. The main drawback of a coarse resolution imagery is related to heterogeneity of pixels which often contain several agricultural fields covered by different crops or even by non-agricultural land. MODIS sensors mounted aboard the Terra and Aqua satellites provide $250 \mathrm{~m}$ imagery in the red and near infrared bands which are crucial for vegetation studies. Consequently many studies incorporated MODIS data to forecast crop yields $[9,19,26,27]$. Nevertheless, the MODIS instruments operating since 1999 (Terra platform) and 2002 (Aqua platform) several times exceeded the expected 6 years of mission duration. Therefore, in this study we employ data from Sentinel-3 satellite constellation (designed to operate till 2032) to operationally acquire near-real time vegetation indices at 300-meter resolution. However, in order to compute temporal anomalies we have extended the Sentinel-3 time series with MODIS measurements, re-calibrated to match the Sentinel-3 signal.

Within this study we propose a novel system for an operational crop yield forecasting at Nomenclature des Unités Territoriales Statistiques level 2 (NUTS-2) and Local Administrative Units (LAU) that builds on a fusion of satellite-based vegetation indices, agro-meteorological indicators, and crop phenology approximated by thermal time. The system exploits Copernicus data sets and climate reanalysis available free-of-charge at a global scale, and thus it can be applied at any location. Within this study we utilize the system for predicting yields of winter wheat, winter rapeseed and maize in Poland for a period 2000-2019. To build a system, the first specific objective is to calibrate vegetation indices from Sentinel-3, that are used operationally, with MODIS data which extends the data record to the period before 2018. A second specific objective is to verify the applicability of ERA-5 climate reanalysis data to describe agro-meteorological conditions that affect crop development. A third specific objective is to quantify the impact of the length of the time series used to train the forecasting models, that differs depending on the availability of reference crop yield statistics, on the model performance. Finally, the details on numerical implementation of the system are provided.

\section{Data}

\subsection{Satellite data}

\subsubsection{Sentinel-3 operational products}

The Level-2 Near Real Time (NRT) products (i.e. surface reflectance, vegetation indices, land surface temperature) acquired by the Ocean and Land Colour Imager (OLCI) and Sea and Land Surface Temperature Radiometer (SLSTR) mounted onboard Sentinel-3 satellites are freely available from the Copernicus Open Access Hub (https: / / scihub.copernicus.eu/ accessed on 20.11.2021) with a delay up to 3 hours after satellite acquisition. The following daily products from the Sentinel-3A and Sentinel-3B satellites for 2018-2020 were used in this study:

1. Land Full Resolution (LFR) product derived from OLCI imagery at $300 \mathrm{~m}$ resolution consisting of Global Vegetation Index (OGVI) and Terrestrial Chlorophyll Index (OTCI) indices accompanied with rectified reflectances at $681 \mathrm{~nm}$ (RED) and $865 \mathrm{~nm}$ (NIR) channels used in this study to calculate Normalized Difference Vegetation Index (NDVI) using formula: NDVI=(NIR-RED)/(RED+NIR); 


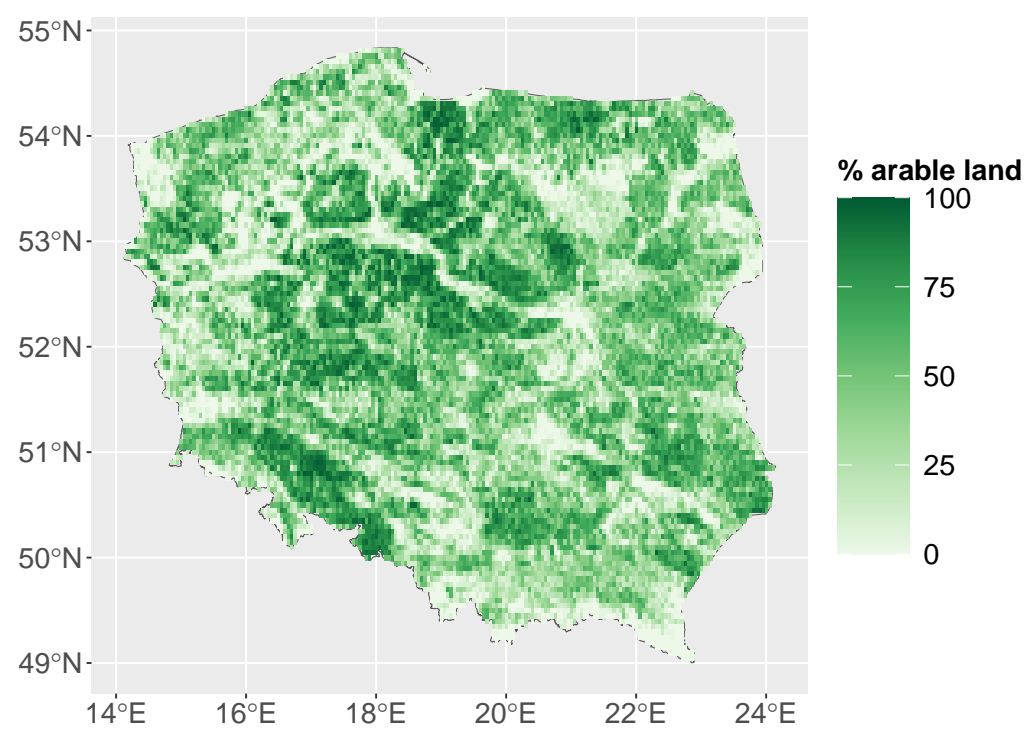

Figure 1. Fractional arable land [\%] in Poland.

2. Land surface temperature (LST) from SLSTR sensor at $1 \mathrm{~km}$ resolution.

The acquired products were further mosaicked, cloud masked using associated quality flags and reprojected to the Poland CS92 coordinate system (EPSG: 2180) using ESA SNAP software.

\subsubsection{MODIS products}

The MOD09Q1, MOD11A2 collection 6 (V006) products generated from the ModerateResolution Imaging Spectroradiometer (MODIS) imagery are freely available from the Land Processes Distributed Active Archive Center (LP DAAC) of the U.S. Geological Survey (https://lpdaac.usgs.gov accessed on 20.11.2021). The acquired products covered Poland and the period 2000-2019. The MOD09Q1 product contains 8-day composites of land surface spectral reflectance acquired in the 620-670 nm (RED) and 841-876 nm (NIR) channels at $250 \mathrm{~m}$ resolution, which were used to calculate NDVI. Information on the presence of clouds, cloud shadows, and snow was derived from the associated quality flags. The MOD11A2 product provides 8-day composites of daytime and night-time LST and emissivity calculated from the $11.03 \mu \mathrm{m}$ and $12.02 \mu \mathrm{m}$ channels at a spatial resolution of $1 \mathrm{~km}$. The NDVI and LST MODIS products were mosaicked and reprojected to the Poland CS92 coordinate system (EPSG: 2180).

\subsection{Agro-meteorological data}

Agro-meteorological data for a period 2000-2019 at $0.25 \times 0.25$ deg resolution were derived from the ERA- 5 reanalysis generated by the European Centre for Medium-Range Weather Forecasts and freely distributed through the Copernicus Climate Data Store. They included hourly data at surface level consisting of: 2-meter air temperature, total precipitation, surface incoming solar radiation, and volumetric soil water at $0-7 \mathrm{~cm}$ and 7-28 cm depths. These parameters were aggregated into daily means and/or sums using Climate Data Operators (CDO) software [28]. Additionally, minimum and maximum daily air temperatures were calculated.

\subsection{Crop mask}

A binary crop mask was derived from the Corine Land Cover version 2018 classification, freely distributed by the European Environmental Agency (EEA) at https:/ / land.copernicus.eu/pan-european/corine-land-cover/clc2018 (accessed on 20.11.2021), by extracting 2.1.1 (Non-irrigated arable land) and 2.4.2 (Complex cultivation patterns) 


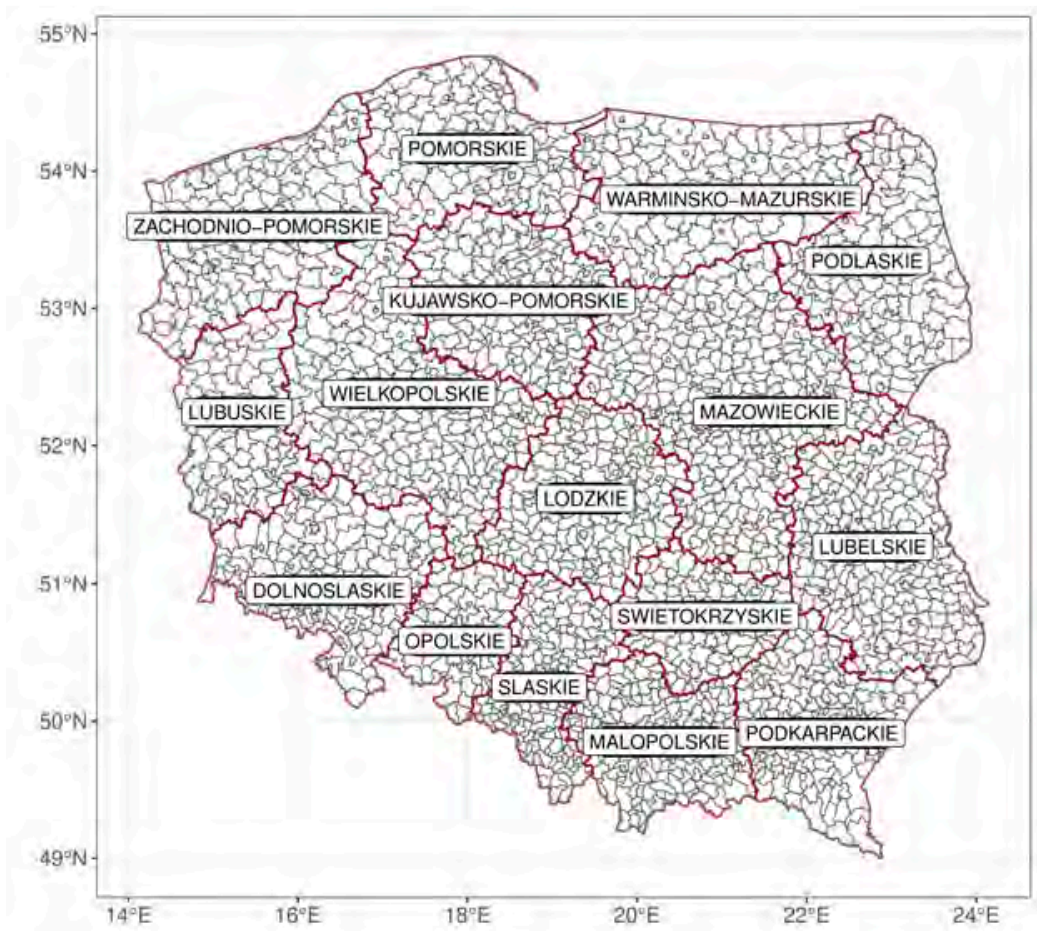

Figure 2. Administrative divisions of Poland for which crop yields were predicted: NUTS-2 (red lines) and LAU (grey lines).

classes as arable land. Further, the binary mask was used to generate fractional arable land products at spatial resolutions matching the Sentinel-3, MODIS and ERA-5 products. These fractional estimates were used as weights to spatially aggregate satellite and agro-meteorological variables for the administrative units. Example of fractional arable land over Poland is presented in Figure 1.

\subsection{Crop yield statistics}

The reference data for the crop yield forecasting model consisted of official yield statistics provided by Statistics Poland at NUTS-2 and LAU levels (Figure 2). The NUTS2 data included winter wheat, winter rapeseed and maize yields expressed in decatons [dt] for the period 1997-2019. At the LAU level the length of the time series was shorter, and also inconsistent among administrative units (Figure 3).

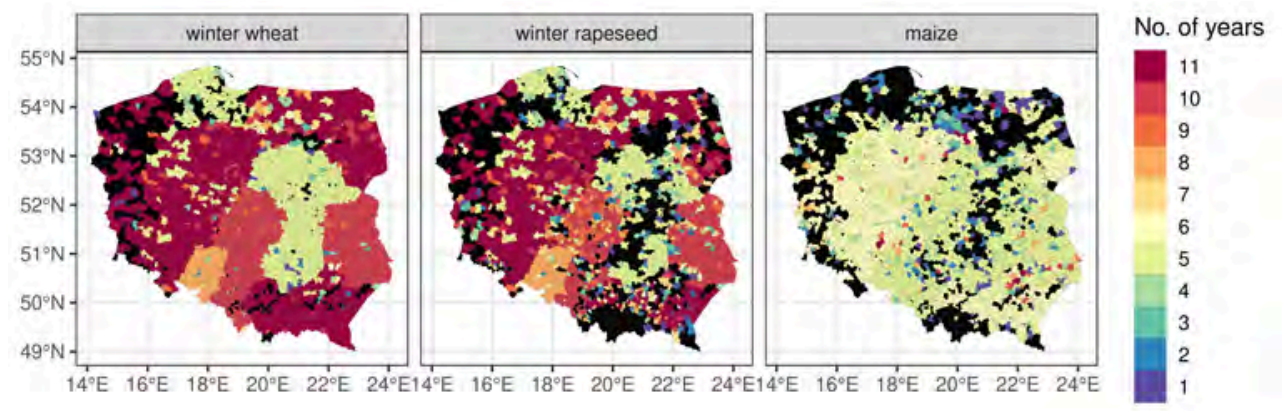

Figure 3. Time span of official crop yield statistics at the LAU level. Black signifies no data. 


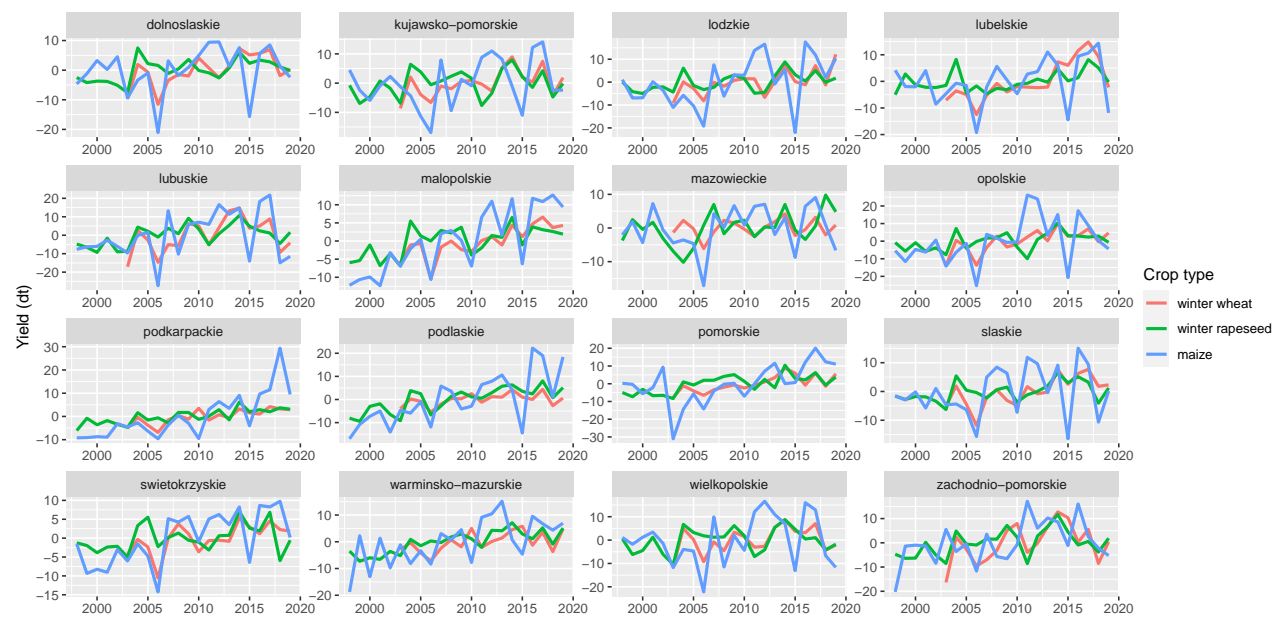

Figure 4. Temporal yield residuals from Theil-Sen monotonic trend used as a response variable in crop yield forecasting for NUTS-2. Please mind different limits of Y-axes.
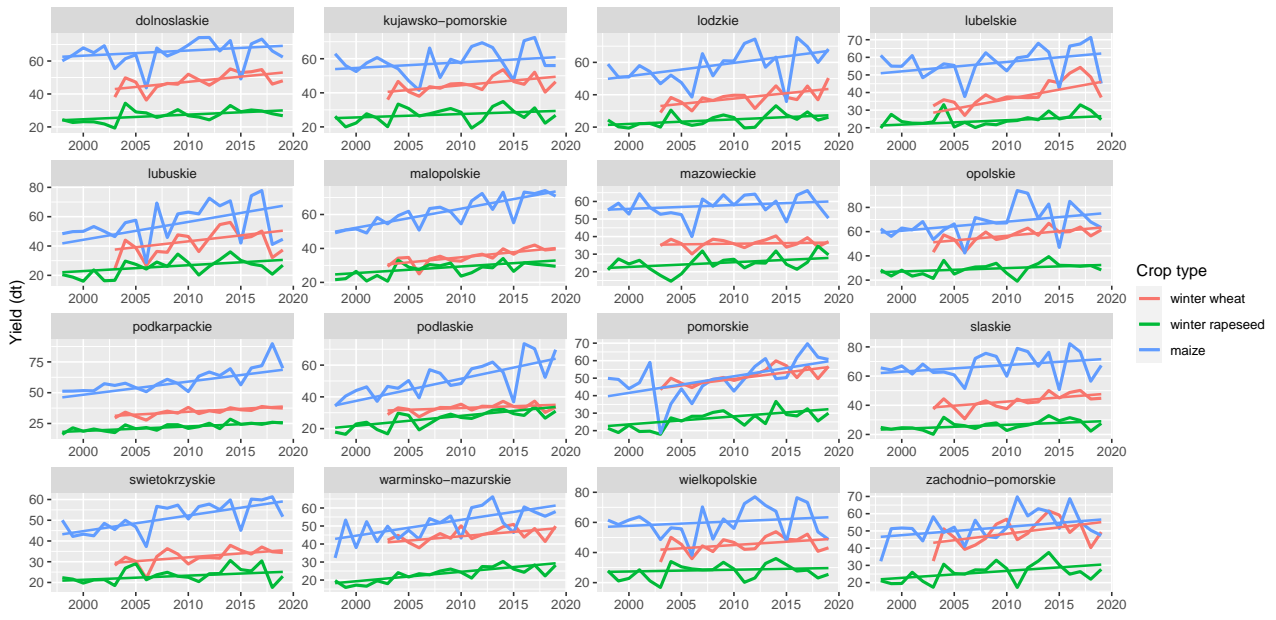

Figure 5. Absolute annual crop yields for NUTS-2 units reported by the Statistics Poland with fitted Theil-Sen monotonic trend. Please mind different limits of Y-axes.

The yield statistics for each NUTS-2 and LAU region were transformed into temporal yield residuals (Figure 4) from the Theil-Sen monotonic trend [29] in annual yields estimates covering the period 1997-2019 (Figure 5). These yield residuals were used as response variables in crop yield forecasting. The final absolute yield forecast consisted of a sum of the monotonic trend and a forecasted yield residual for a particular year.

\section{Methods}

\subsection{Spatial aggregation}

Data derived from MODIS, Sentinel-3 and ERA-5 products were spatially aggregated for arable land (using a crop mask) within administrative units (NUTS-2 and LAU) (Table 1). The aggregation followed the approach proposed by Genovese et al. (2001) [30] where the products were initially masked whenever a fraction of arable land within a pixel is less than $30 \%$. The remaining pixels were averaged within administrative units using the fraction of arable land as weights. Additional adjustment of weights at the borders between administrative units was performed to reduce the importance of pixels covered by more than one unit. The aggregation resulted in a database consisting of predictors at NUTS-2 and LAU administrative levels averaged from MODIS, Sentinel-3 and ERA-5 products at native temporal resolution (see Table 1). 
Table 1. Satellite, agro-meteorological and ancillary data used to derive crop yield forecast predictors.

\begin{tabular}{|c|c|c|c|}
\hline Name & Source & $\begin{array}{c}\text { Temporal } \\
\text { resolution }\end{array}$ & $\begin{array}{c}\text { Spatial } \\
\text { resolution }\end{array}$ \\
\hline \multicolumn{4}{|c|}{ Satellite indices } \\
\hline NDVI (-) & MODIS & 8 day & $250 \mathrm{~m}$ \\
\hline NDVI (-) & Sentinel-3 & 1 day & $300 \mathrm{~m}$ \\
\hline LST (K) & MODIS & 8 day & $1000 \mathrm{~m}$ \\
\hline LST (K) & Sentinel-3 & 1 day & $1000 \mathrm{~m}$ \\
\hline \multicolumn{4}{|c|}{ Agro-meteorological parameters } \\
\hline Air temperature $(\mathrm{K})$ & ERA-5 & 1 hour & $0.25 \mathrm{deg}$ \\
\hline Precipitation $(\mathrm{m})$ & ERA-5 & 1 hour & $0.25 \mathrm{deg}$ \\
\hline Surface radiation $\left(\mathrm{J} \mathrm{m}^{-2}\right)$ & ERA-5 & 1 hour & $0.25 \mathrm{deg}$ \\
\hline Soil moisture $0-7 \mathrm{~cm}\left(\mathrm{~m}^{3} \mathrm{~m}^{-3}\right)$ & ERA-5 & 1 hour & $0.25 \mathrm{deg}$ \\
\hline Soil moisture $7-28 \mathrm{~cm}\left(\mathrm{~m}^{3} \mathrm{~m}^{-3}\right)$ & ERA-5 & 1 hour & $0.25 \mathrm{deg}$ \\
\hline \multicolumn{4}{|c|}{ Crop mask } \\
\hline Fraction of arable land & CLC $^{*} 2018$ & static & Polygons** \\
\hline \multicolumn{4}{|c|}{ Administrative units } \\
\hline NUTS-2/LAU & $\mathrm{GUGiK}^{* * *}$ & static & Polygons \\
\hline
\end{tabular}

\subsection{Temporal smoothing of NDVI values}

A 2-iterative cubic spline smoothing technique was applied to filter out spurious NDVI values (MODIS and Sentinel-3) introduced by residual cloud cover and/or by geolocation errors. This technique assumes that residual cloud cover decreases NDVI values. Therefore, in a first step the smoothing method fitted a spline to the original data. Then, the distance (difference) between the fit and the original values created weights so that the original values above the spline fit received high weights and the values below initial fit received weights equal to 0 . Finally, the smoothed NDVI was generated by the second cubic spline fit that uses these weights.

\subsection{Cross-calibration of NDVI and LST products derived from MODIS and Sentinel-2 data}

The temporal homogeneity of NDVI- and LST-based indices is crucial to derive reliable anomalies that could serve as crop yield predictors. Therefore, the MODIS NDVI and LST time series were cross-calibrated with analogous Sentinel-3 products to form homogenous data records. The calibration method built on the automatic selection of the optimal machine learning method amongst: Random Forest (RF), k-Nearest Neighbor (kNN), Support-vector machine (SVM) and Neural Network (NN), which yielded the largest modelling efficiency (EF) (formula given in Section 3.6) between re-calibrated MODIS time series and corresponding original Sentinel-3 time series. The training and validation of machine learning techniques were performed for the period 2018-2020 when both MODIS and Sentinel-3 satellites were operational. The validation followed the leave-one-year-out approach to choose the most accurate machine learning method, which has occurred to vary for different data sets. To model the differences between MODIS and Sentinel-3 indices three explanatory variables were used. The first one was calendar time expressed as a day of the year. The second explanatory variable was thermal time expressed by the growing degree days (see Section 3.4 for details) indicating the amount of thermal energy accumulated at a given time and the amount of energy needed to reach a given stage of crop development. Third explanatory variable was 
MODIS product (i.e. NDVI or LST) to be homogenised with the Sentinel-3 counterpart. Ultimately, the trained calibration models were applied to MODIS NDVI and LST time series between years 2000 and 2017 to extend the Sentinel-3 time series.

\subsection{Resampling of explanatory variables from calendar time to thermal time}

To ensure year-to-year comparability of vegetation conditions, the explanatory variables were resampled from calendar time (day of year) to thermal time, which denotes cumulated mean daily air temperatures at $2 \mathrm{~m}$ a.g.l above a crop-specific threshold. Thus a thermal time is a good proxy for the crop development stage [31-33]. Analysis of vegetation indices in respect to thermal time allows derivation of temporal anomalies by referring instantaneous values of an index to a multiannual average calculated for the same thermal time (i.e. the same crop development stage). If the calendar time was used instead of the thermal time, the temporal anomalies could be related to the shift in a vegetation season (e.g. a delay in biomass accumulation) but not to the actual crop conditions that are to be used to forecast crop yields.

Thermal time was calculated for a day $d$ of the year as so-called growing degree days (GDD) from daily maximum $\left(T_{\max }\right)$ and minimum $\left(T_{\min }\right)$ air temperatures using a formula:

$$
\mathrm{GDD}_{d}=\sum_{i=1}^{d}[\left(\frac{T_{\max , i}+T_{\min , i}}{2}-T_{\text {base }}\right) \times \underbrace{\left[\left(\frac{T_{\max , i}+T_{\min , i}}{2}-T_{\text {base }}\right)>0\right]}_{\text {conditional }}]
$$

where $T_{\text {base }}$ stands for crop-specific temperature threshold: $5{ }^{\circ} \mathrm{C}$ for winter wheat and winter rapeseed, and $10^{\circ} \mathrm{C}$ for maize. In addition, $T_{\min , i}$ equals $T_{\text {base }}$ if $T_{\min , i}<T_{\text {base, }}$ and $T_{\max , i}$ equals $30^{\circ} \mathrm{C}$ if $T_{\max , i}>30^{\circ} \mathrm{C}$. The conditional part of the equation equals 1 if the condition is met, and 0 otherwise, which implies that only positive values (mean air temperature values reduced by the threshold) are summarized. Based on daily GDD values, all yield predictors were resampled for eight GDD values ranging from $150{ }^{\circ} \mathrm{C}$ to $1200{ }^{\circ} \mathrm{C}$ with a step of $150{ }^{\circ} \mathrm{C}$.

Resampling of NDVI and LST to thermal time allowed derivation of normalized indicators proposed by Kogan (1997) [34] such as: Vegetation Condition Index (VCI) and Temperature Condition Index (TCI) defined as:

$$
\begin{gathered}
\mathrm{VCI}_{\mathrm{GDD}}=100 \times \frac{\mathrm{NDVI}_{\mathrm{GDD}}-\mathrm{NDVI}_{\mathrm{min}, \mathrm{GDD}}}{\mathrm{NDVI}_{\max , \mathrm{GDD}}-\mathrm{NDVI}_{\min , \mathrm{GDD}}} \\
\mathrm{TCI}_{\mathrm{GDD}}=100 \times \frac{\mathrm{LST}_{\max , \mathrm{GDD}}-\mathrm{LST}_{\mathrm{GDD}}}{\mathrm{LST}_{\max , \mathrm{GDD}}-\mathrm{LST}_{\min , \mathrm{GDD}}}
\end{gathered}
$$

where GDD indicates the growing degree days (thermal time), $\mathrm{NDVI}_{\mathrm{GDD}}$ - an instantaneous NDVI value, and $\mathrm{NDVI}_{\min }$, GDD and $\mathrm{NDVI}_{\max }, \mathrm{GDD}$ - minimum and maximum NDVI recorded in the period 2000-2019 at a particular location for a given GDD, respectively. Definition of $\mathrm{TCI}_{\mathrm{GDD}}$ follows the same logic as $\mathrm{VCI}_{\mathrm{GDD}}$.

\subsection{Crop yield forecasting}

Crop yield forecasting proposed in this study employs machine learning technique i.e. eXtreme Gradient Boosting (XGBoost) algorithm [35] to predict crop yield residuals from Theil-Sen monotonic trend using a variety of predictors derived from satellite and agrometeorological data. To train the XGBoost method an extensive input table was constructed for each administrative unit (LAU or NUTS-2) consisting of $r$ rows and $c$ columns, where $r$ denotes a number of years for which predictors and reference crop yields were available, and $c$ indicates a number of predictors. The following predictors were calculated for each of eight GDD levels $\left(150^{\circ} \mathrm{C}, 300^{\circ} \mathrm{C}, 450{ }^{\circ} \mathrm{C}, \ldots, 1200^{\circ} \mathrm{C}\right)$ : 
- $\quad$ minimum, maximum and mean air temperature;

- $\quad$ surface radiation;

- $\quad$ accumulated surface radiation since April $1^{\text {st }}$;

- $\quad$ soil moisture at 0-7 cm and 7-28 cm levels;

- precipitation;

- $\quad$ accumulated precipitation since April $1^{\text {st }}$;

- $\mathrm{NDVI}_{\mathrm{GDD}}$;

- $\mathrm{VCI}_{\mathrm{GDD}}$;

- LST $_{\mathrm{GDD}}$;

- $\mathrm{TCI}_{\mathrm{GDD}}$;

- $\quad$ annual maximum NDVI (which does not correspond to the GDD levels).

In total there were 170 predictors $(c)$ but the number of years $(r)$ varied between crop types and administrative units due to the reference data availability. For LAUs the number of years is presented in Figure 3, whereas for NUTS-2 it equalled 17 for winter wheat and 22 for winter rapeseed and maize.

All predictors were linearly scaled to the range between zero and one. Then, highly correlated predictors (above 0.75 ) were removed. Further, the feature selection procedure was applied based on the recursive feature elimination [36] employing the XGBoost method. The optimized XGBoost algorithm was ultimately trained based on selected predictors and crop yield residuals as a dependent variable. The application of the prediction model resulted in the forecasted crop yield residuals. The final absolute yield forecast was then calculated as a sum of this value and the crop yield estimated from the Theil-Sen monotonic trend.

\subsection{Validation approach}

Validation of forecasting models involved the comparison of predicted yields and reference official statistics that were not used for the model training. For each administrative unit, each crop type and each GDD level, a cross-validation was thus performed. It followed the leave-one-year-out procedure which is a special case of the $k$-fold cross validation where $k$ equals a number of years in a time series. It has to be noted that the selection of predictors was repeated at each iteration to avoid the predictor selection procedure to benefit from 'knowing' the data from the year that was used for validation.

Three metrics were used to describe the model performance: MBE (Mean Bias Error), RMSE (Root Mean Square Error) and EF (Modelling Efficiency) calculated by means of the following formulae:

$$
\begin{gathered}
\mathrm{MBE}=\frac{1}{n} \sum_{k=1}^{n}\left(E_{k}-M_{k}\right) \\
\mathrm{RMSE}=\sqrt{\frac{1}{n} \sum_{k=1}^{n}\left(E_{k}-M_{k}\right)^{2}} \\
\mathrm{EF}=1-\frac{\sum_{k=1}^{n}\left(E_{k}-M_{k}\right)^{2}}{\sum_{k=1}^{n}\left(E_{k}-\bar{M}\right)^{2}}
\end{gathered}
$$

where: $E_{k}$ - predicted crop yield value, $M_{k}$-- reference crop yield value, $\bar{M}$ - average value of reference crop yield values, $k$ - step of the time series (i.e. 1 year), and $n$ - length of the time series.

The RMSE and MBE were also expressed in relative values (0-100\%) denoted as the RRMSE and RMBE respectively, by dividing these quality metrics by the mean of a reference data $(\bar{M})$. The MBE, RMSE and EF were also used to evaluate the accuracy of cross-calibration between MODIS and Sentinel-3 products. However, in this situation the $E_{k}$ denotes re-calibrated MODIS NDVI/LST and $M_{k}$ the original Sentinel-3 NDVI/LST time series. 

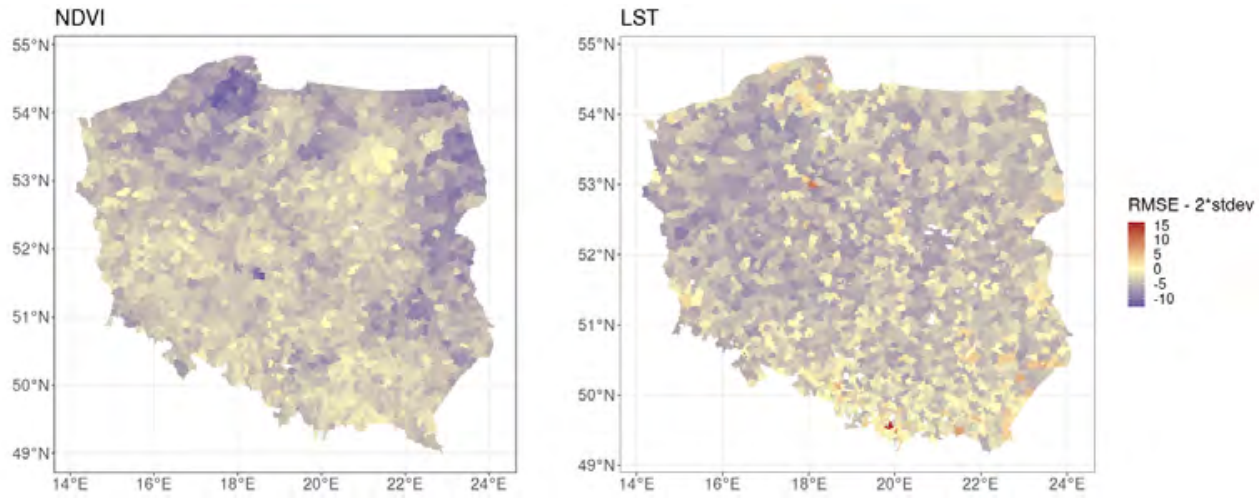

Figure 6. Monthly differences (May) for LAU units between cross-calibration error (RMSE) and the natural variability of the MODIS-derived predictors expressed as double standard deviation. The negative differences (blue colours) indicate that the calibration error is lower than the natural variability.

\section{Results}

\subsection{Accuracy of cross-calibration between MODIS and Sentinel-3 products}

The most accurate calibration models homogenizing MODIS NDVI and LST products with Sentinel-3 counterparts are given in Table 2. The RF and kNN models were found to be the optimal for the cross-calibration of NDVI and LST, respectively.

Table 2. Accuracy of MODIS NDVI and LST cross-calibration to Sentinel-3 counterparts.

\begin{tabular}{cccccc}
\hline $\begin{array}{c}\text { Response } \\
\text { variable }\end{array}$ & Status & Predictors & MBE & RMSE & EF \\
\hline NDVI $_{S-3}$ & prior to calibration & - & 3.40 & 5.16 & 0.73 \\
NDVI $_{S-3}$ & calibrated by RF & NDVI $_{\text {MODIS, DOY, GDD }}$ & 0.07 & 2.95 & 0.91 \\
LST $_{S-3}$ & prior to calibration & - & -7.16 & 7.83 & -0.65 \\
LST $_{S-3}$ & calibrated by kNN & LST $_{\text {MODIS, DOY, GDD }}$ & 0.00 & 2.51 & 0.84 \\
\hline DOY - Day of Year; S-3 - Sentinel-3; GDD - Growing Degree Days & & &
\end{tabular}

Table 2 reveals clear improvement in time series homogeneity between MODIS and Sentinel-3, which is confirmed by all three quality metrics. Yet, the impact of the remaining difference between Sentinel-3 and MODIS products on time series homogeneity is not easy to determine. This in turn may have further implications on the reliability of crop yield predictors that are calculated as anomalies or standardized by extreme values (i.e. VCI, TCI). To compare the spurious temporal variability introduced by the cross-calibration with natural variability of MODIS-derived predictors (NDVI, LST), the differences between monthly cross-calibration RMSE and double monthly standard deviations of MODIS-derived predictors within the period 2000-2019 were computed and revealed for administrative units (Figure 6). The negative differences (marked with blue color) indicate that the cross-calibration error is lower than the natural variability of a predictor expressed by the double standard deviation. Overall, such a situation for NDVI occurred in $78 \%$ of LAU units and for LST in $98 \%$ of LAU units. This implies that in a great majority of administrative units the cross-calibration errors do not obscure the natural variability of the predictors. Thus, it can be concluded that the developed and validated cross-calibration models are sufficient to homogeneize MODIS products with the Sentinel-3 counterparts and further to use the homogenized data records to predict crop yields. 


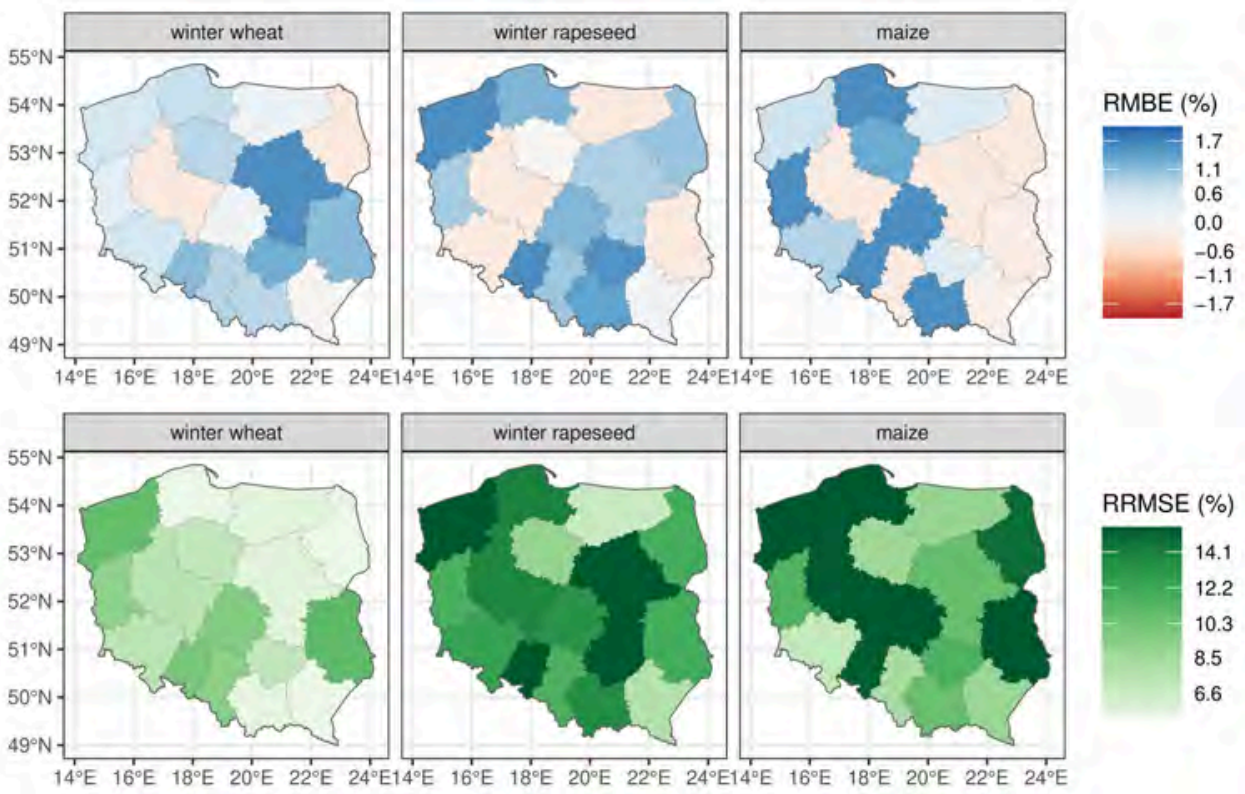

Figure 7. Map of crop yield forecasts performance at the NUTS-2 level.

\subsection{Yield forecasting performance}

\subsubsection{NUTS-2 level}

The best performance of end-of-season crop yield predictions is revealed for winter wheat $($ RRMSE $=8.15 \%$ ), while predictions for maize and winter rapeseed are less accurate $(\mathrm{RRMSE}=13 \%)$. For all three crops, the overall relative bias (RMBE) is below $1 \%$. Yet, for individual NUTS-2 regions these errors can be greater (Figure 7).

Table 3. Overall performance of crop yield forecasts at NUTS-2 level.

\begin{tabular}{ccccccc}
\hline Crop type & $\begin{array}{c}\text { MBE } \\
(\mathbf{d t})\end{array}$ & $\begin{array}{c}\text { RMBE } \\
(\mathbf{\%})\end{array}$ & $\begin{array}{c}\text { RMSE } \\
(\mathbf{d t})\end{array}$ & $\begin{array}{c}\text { RRMSE } \\
\mathbf{( \% )}\end{array}$ & $\begin{array}{c}\mathbf{R}^{2} \\
(-)\end{array}$ & $\begin{array}{c}\text { Correlation } \\
(-)\end{array}$ \\
\hline Winter wheat & 0.25 & 0.60 & 3.43 & 8.15 & 0.84 & 0.92 \\
Winter rapeseed & 0.19 & 0.71 & 3.39 & 13.03 & 0.47 & 0.69 \\
Maize & 0.37 & 0.63 & 7.76 & 13.32 & 0.51 & 0.71 \\
\hline
\end{tabular}

Figure 8 reveals that forecasting quality metrics differ across years. Most evidently the predictions tended to overestimate crop yields: for all three crops in 2006, for winter rapeseed in 2003, and for maize in 2015. Kuśmierek-Tomaszewska and Żarski (2021) [37] reported these years as dry according to the Standardized Precipitation Index (SPI). In 2003 moderately dry conditions in May may have affected rapeseed development. In 2006 , the very dry (SPI < -1.5) period in June-July impacted all crops. Finally, in 2015 drought lasted until the end of season limiting maize yields. Figures 9, 10 and 11 reveal detailed year-by-year performance of the crop yield forecasts for all three crops. High performance of winter wheat yield forecasts for Mazowieckie, Świętokrzyskie, Podkarpackie and Podlaskie NUTS-2 units can be related to low annual variability of yields ranging from 30 to $40 \mathrm{dt}$ /ha (Figure 9) that can be well approximated by a monotonic trend.

The quality of the prediction models increases along the season when more predictors become available for the XGBoost model (after every $150{ }^{\circ} \mathrm{C}$ GDD step). According to correlation coefficient, for winter wheat and winter rapeseed the prediction models on average outperform the Theil-Sen monotonic trend-model at $450{ }^{\circ} \mathrm{C}$ GDD (Figure 12). However, only after mid-season this is valid for the vast majority of administrative units. 


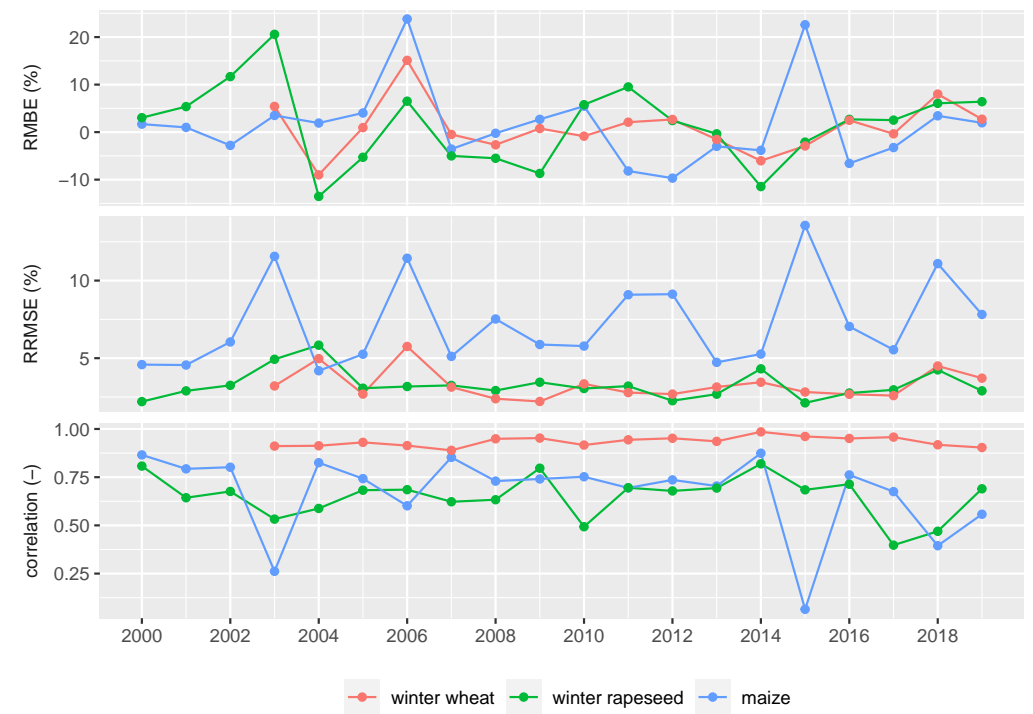

Figure 8. Time series of quality metrics of crop yield predictions for NUTS-2 units after the vegetation season.

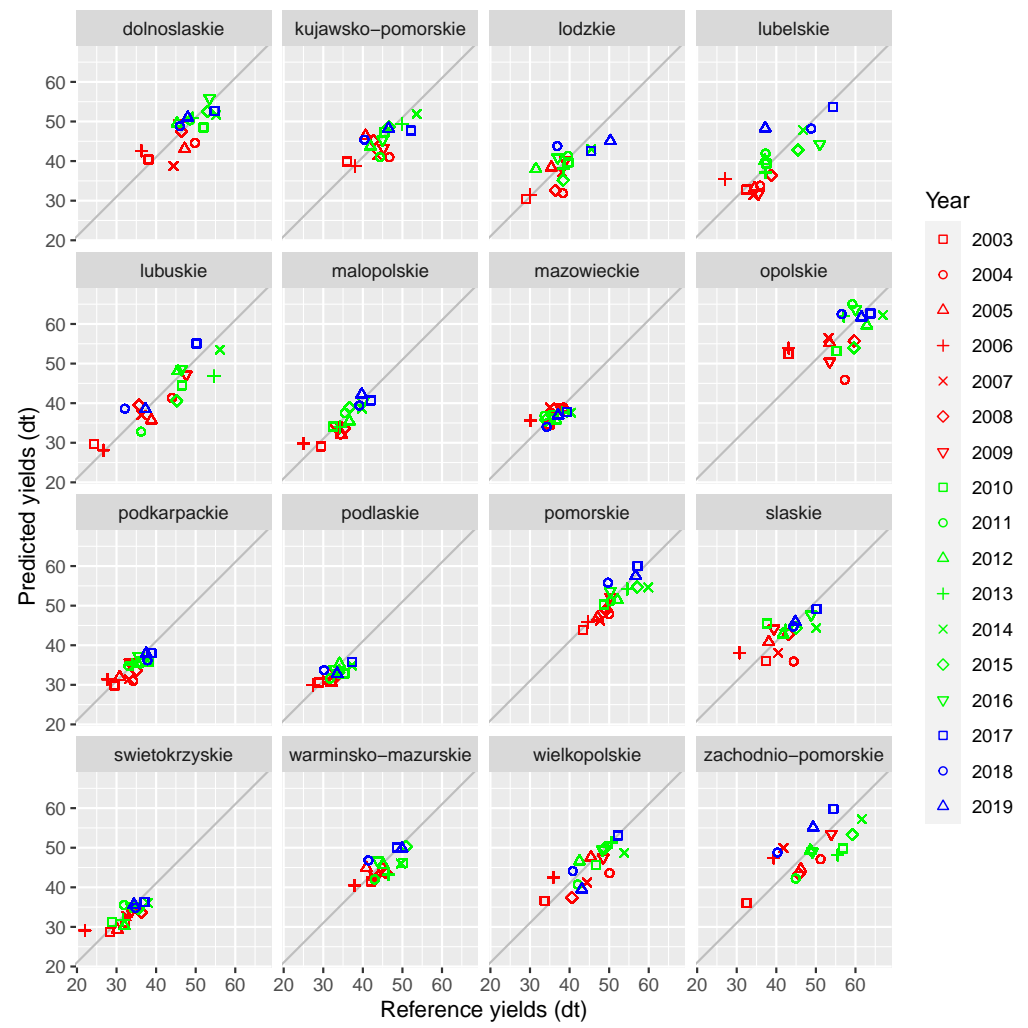

Figure 9. Comparison of crop yield predictions with the reference statistics for winter wheat at NUTS-2 level. 


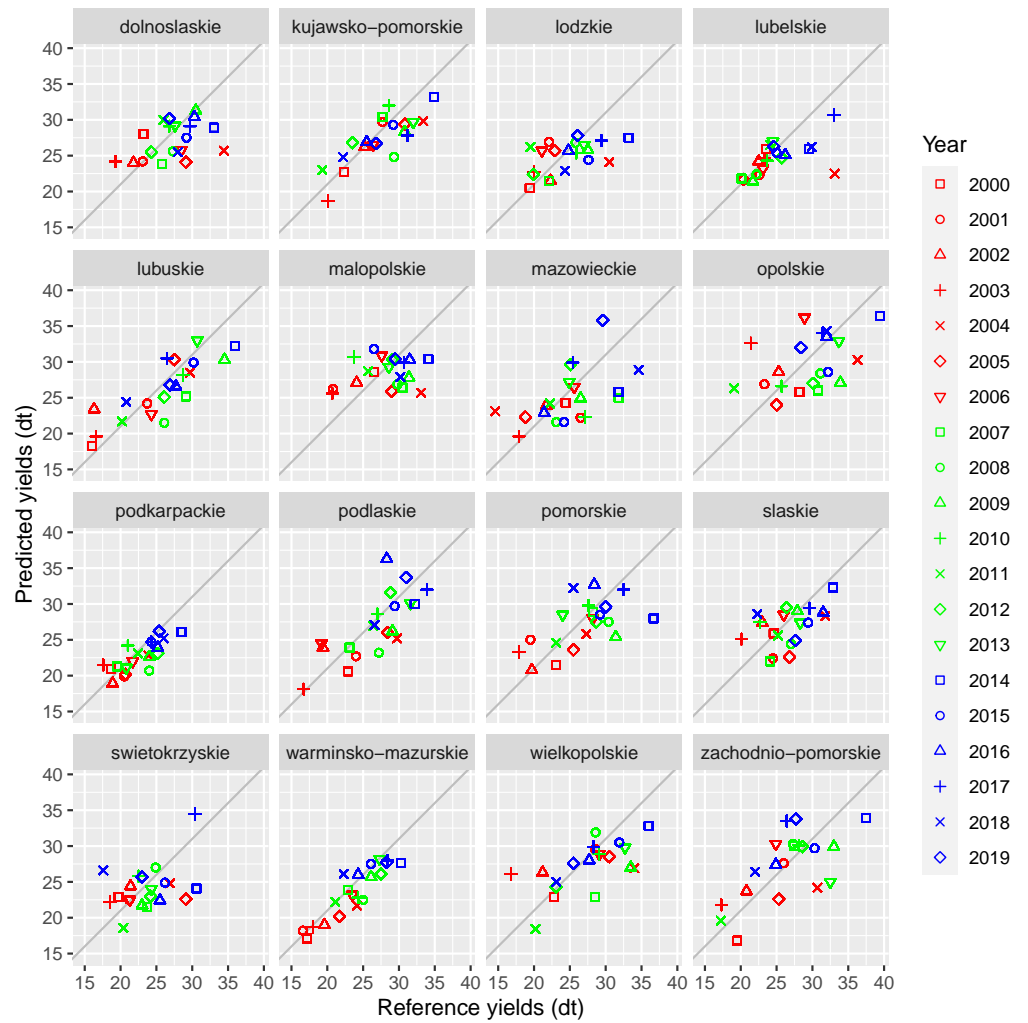

Figure 10. Comparison of crop yield predictions with the reference statistics for winter rapeseed at NUTS-2 level.

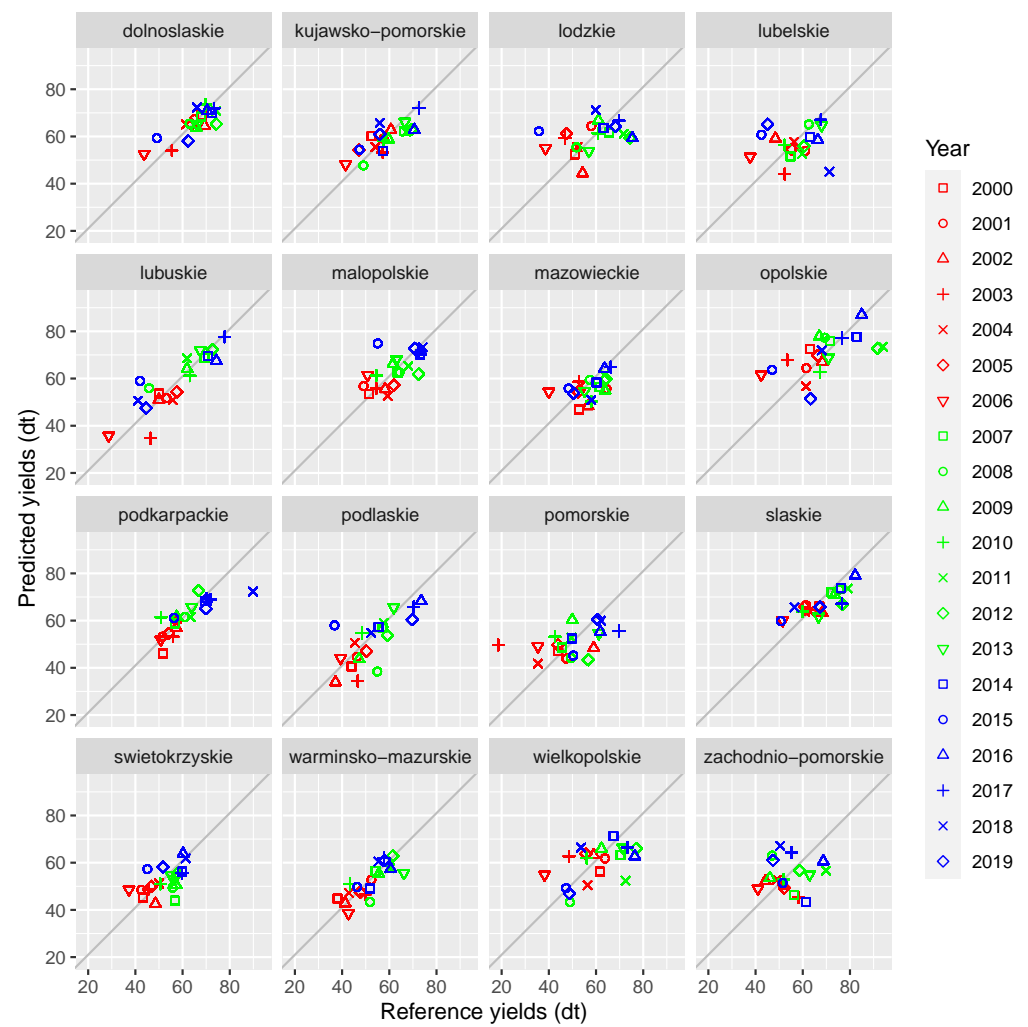

Figure 11. Comparison of crop yield predictions with the reference statistics for maize at NUTS-2 level. 


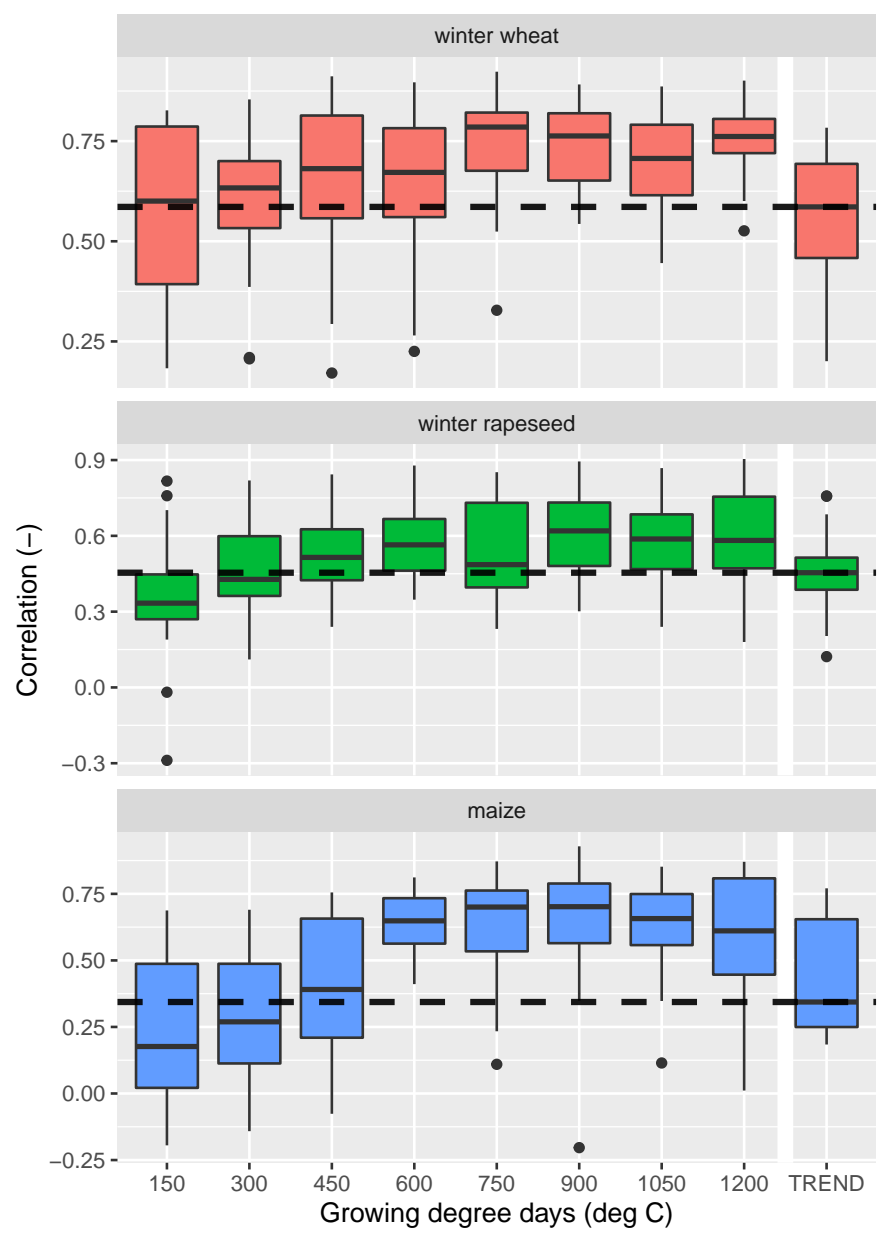

Figure 12. Distributions of temporal correlations for different GDD levels between crop yield predictions and reference statistics. Additionally, the performance of linear trend models is shown on the rightmost box. Dashed line denotes median correlation of the linear trend-model.

For maize it is evident that after $600{ }^{\circ} \mathrm{C}$ GDD the predictions models are significantly more accurate than the trend-model.

\subsubsection{LAU level}

At LAU level, the overall quality of the crop yield predictions is lower than for NUTS-2. The RRMSE is around $14 \%, 19 \%$ and $28 \%$ for winter wheat, winter rapeseed and maize, respectively (Table 4).

Table 4. Overall performance of crop yield forecasts at LAU level.

\begin{tabular}{ccccccc}
\hline Crop type & $\begin{array}{c}\text { MBE } \\
(\mathbf{d t})\end{array}$ & $\begin{array}{c}\text { RMBE } \\
(\mathbf{\%})\end{array}$ & $\begin{array}{c}\text { RMSE } \\
\mathbf{( d t )}\end{array}$ & $\begin{array}{c}\text { RRMSE } \\
\mathbf{( \% )}\end{array}$ & $\begin{array}{c}\mathbf{R}^{2} \\
(-)\end{array}$ & $\begin{array}{c}\text { Correlation } \\
(-)\end{array}$ \\
\hline Winter wheat & -0.01 & -0.03 & 5.20 & 13.77 & 0.75 & 0.87 \\
Winter rapeseed & -0.02 & -0.07 & 5.09 & 18.80 & 0.45 & 0.67 \\
Maize & 0.07 & 0.12 & 14.89 & 27.36 & 0.48 & 0.69
\end{tabular}

Figure 13 presents the quality metrics for LAU units for which crop yields forecasts were generated. Some LAU units lack predictions (marked with black color) due to insufficient reference statistics used to train the XGBoost models or because a given crop is not cultivated there. 


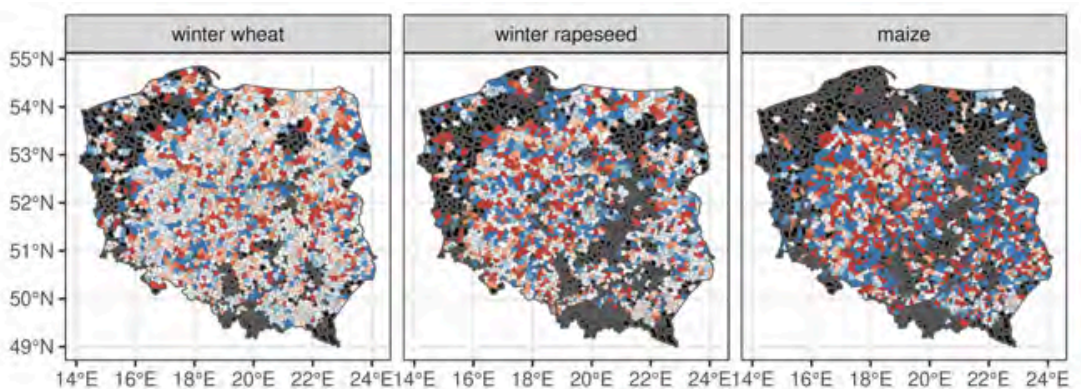

RMBE (\%)
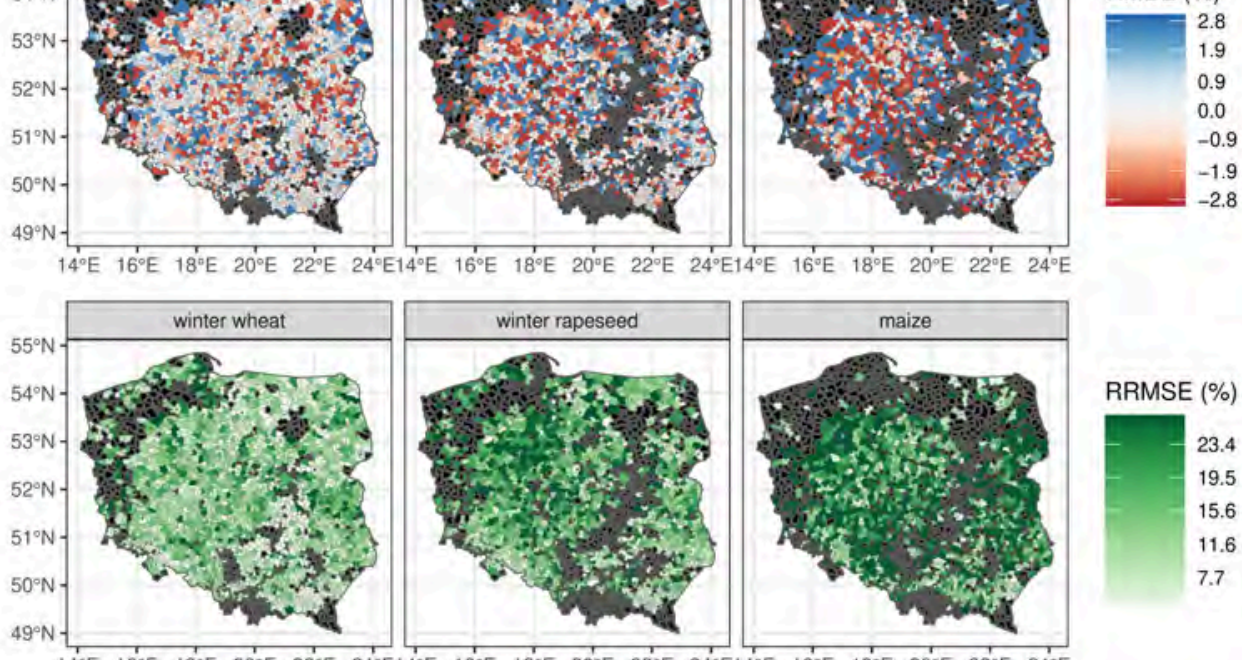

RRMSE (\%)

23.4

19.5

15.6

11.6

$14^{\circ} \mathrm{E} \quad 16^{\circ} \mathrm{E} \quad 18^{\circ} \mathrm{E} \quad 20^{\circ} \mathrm{E} 22^{\circ} \mathrm{E} 24^{\circ} \mathrm{E} 14^{\circ} \mathrm{E} \quad 16^{\circ} \mathrm{E} \quad 18^{\circ} \mathrm{E} \quad 20^{\circ} \mathrm{E} \quad 22^{\circ} \mathrm{E} 24^{\circ} \mathrm{E} 14^{\circ} \mathrm{E} \quad 16^{\circ} \mathrm{E} \quad 18^{\circ} \mathrm{E} \quad 20^{\circ} \mathrm{E} \quad 22^{\circ} \mathrm{E} \quad 2^{\circ} \mathrm{E}$

7.7

Figure 13. Map of crop yield forecasts performance at the LAU level. Black areas denote LAU units where the crop yield forecast was not possible due to data availability issues.

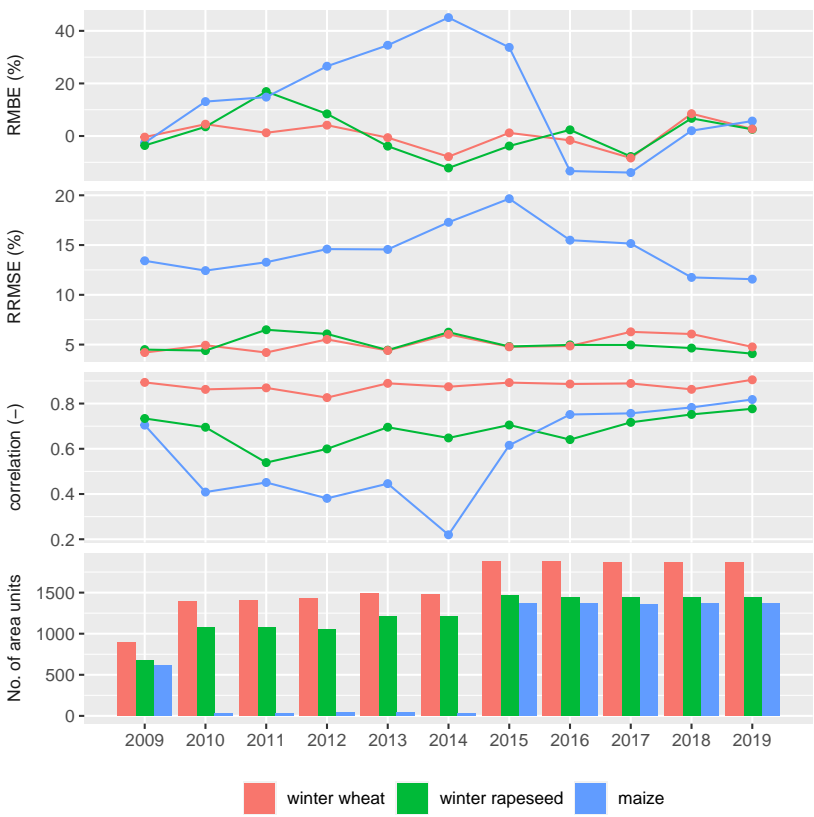

Figure 14. Time series of quality metrics of crop yield predictions for LAU units after the vegetation season. 


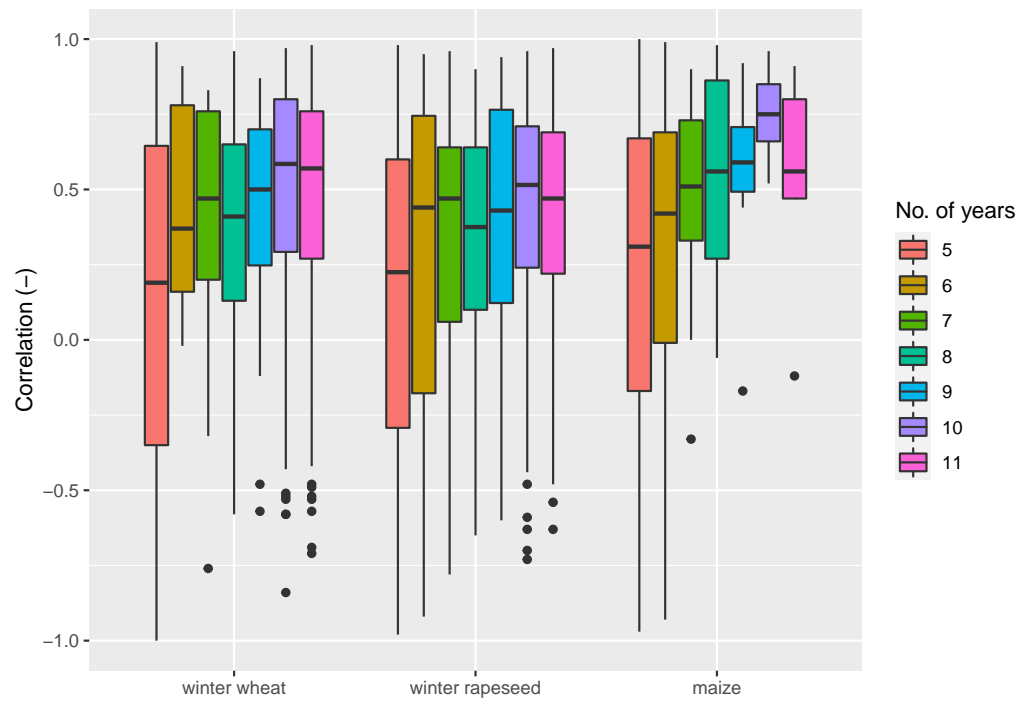

Figure 15. Correlation between reference crop yield statistics (used to train the models) and crop yield forecast as a function of the available time span in years (color bars).

Quality metrics of crop yield forecasts differ from year to year (Figure 14). For winter wheat and rapeseed they are in line with the results for NUTS-2, i.e. overestimation in 2011 (rapeseed) and 2018 (winter wheat). However, overestimated maize yields are strongly related to the amount of data available to train the models (see lowest panel in Figure 14). It can be seen that for the years 2015-2019, for which the amount of data is sufficient, the quality of the forecasts is already close to the NUTS-2 ones. Also the years when the forecast quality is lower are consistent with the NUTS-2 statistics, e.g. for 2015.

Variable length of time series of official statistics (used to train the models) among LAU units allows assessment of how the size of the training dataset impacts the model performance. Figure 15 shows that for all three crops, the larger the training dataset (more years), the higher the accuracy of the crop yield forecasts. This is particularly evident for maize, for which a long data series corresponds to more accurate prediction than for the other two crops.

\section{Implementation of the operational system}

The crop yield forecasting system is fully automatic which implies that data collection, processing, crop yield forecasting and generation of graphical and tabular outputs do not require a human operator. Figure 16 presents the workflow of the crop yield forecasting system along with software that was used at each processing step. The system is implemented as an R package, so any external functions (CDO, Python, SNAP) are called from the R environment. Python is used to retrieve satellite and ERA- 5 data, CDO to process the ERA-5 data, and SNAP to process Sentinel-3 images. Processing of MODIS data, aggregation to administrative units, preparation of predictors, training and application of crop yield models, as well as generation of final outputs are implemented in R. Figure 17 shows an example of graphical system output, which complements the tabular data (CSV) and geospatial vector data (SHP).

To guarantee the portability of the system, everything was installed on a virtual machine (VirtualBox v6.1.20 with Xubuntu v20.04.2). This allows migration to cloud computing environments such as Data and Information Access Services (DIAS) or Amazon Web Services (AWS), where the Copernicus data sets are directly accessible. 


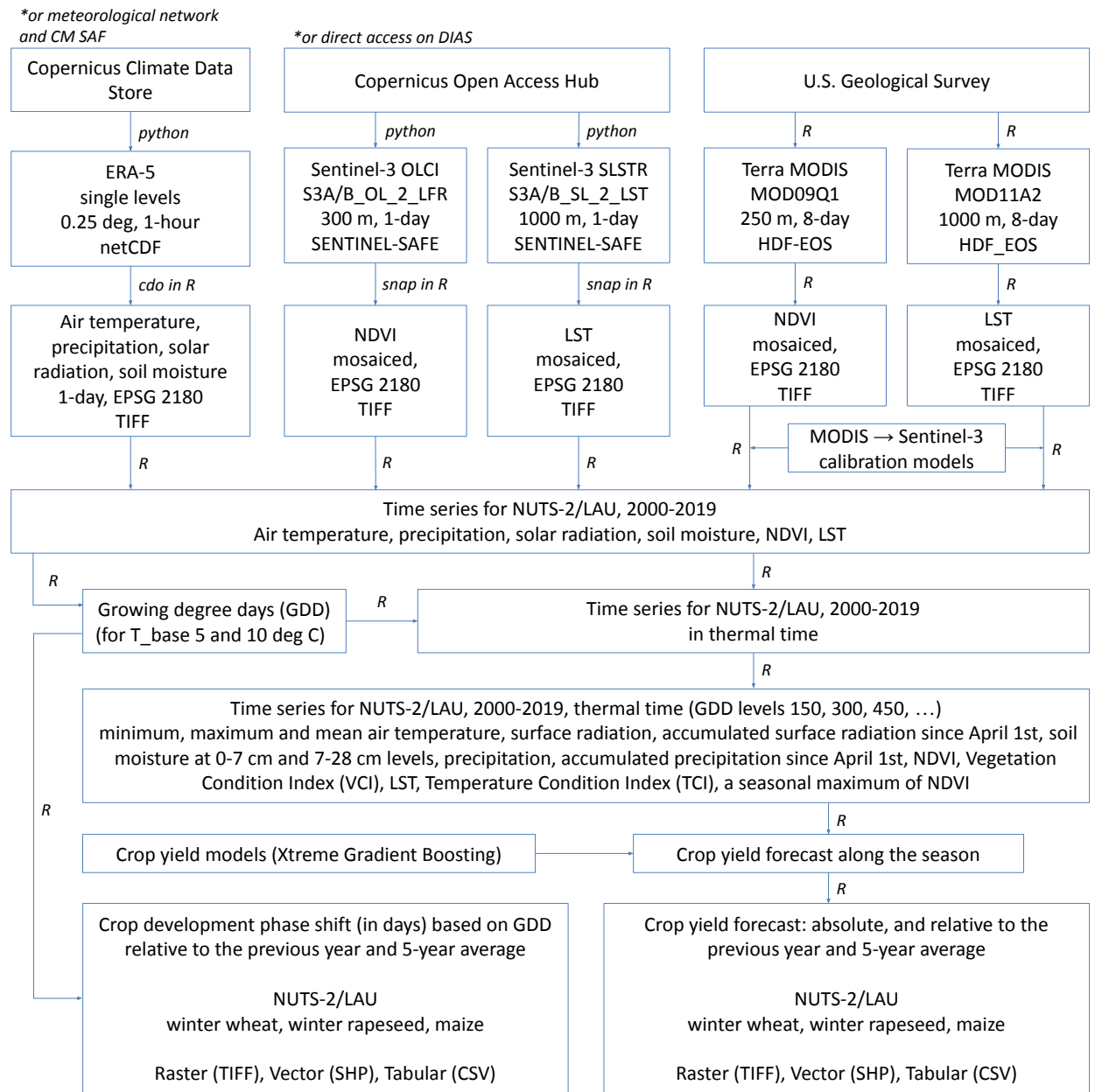

Figure 16. Workflow of the crop yield forecasting system, data streams and software used ('cdo' Climate Data Operators v1.9.9, R v4.1.1, Python v3.8.10). 

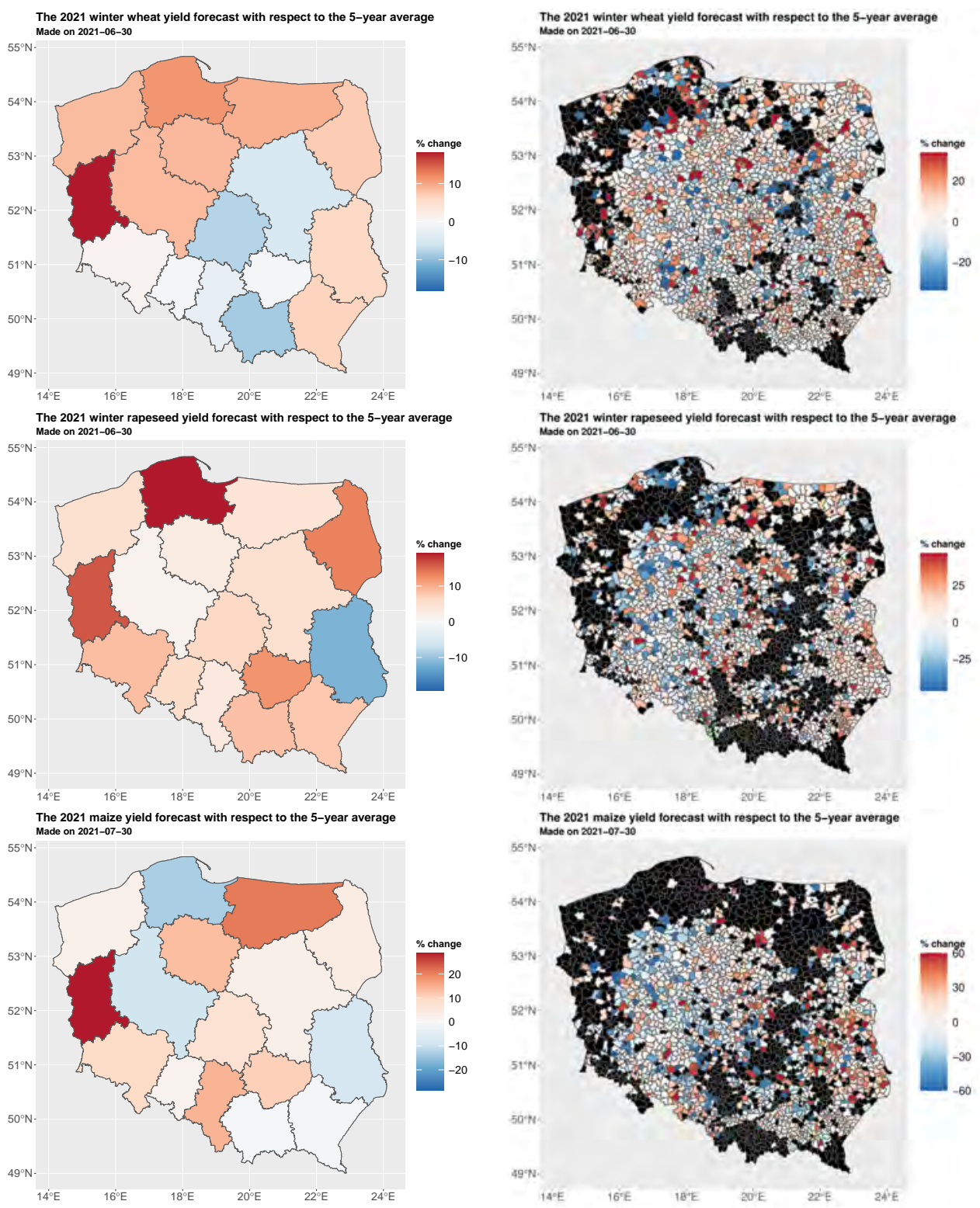

Figure 17. An example of the graphical output generated by the crop yield forecasting system: crop yield forecasts for winter wheat (upper row), winter rapeseed (middle row), and maize (bottom row) for NUTS-2 (left column) and LAU (right column). 


\section{Discussion}

\subsection{Cross-calibration of satellite indices}

The crop yield forecasting system presented here employs the long-term time series of crop growth conditions and corresponding crop yield statistics used to train machine learning models. While agro-meteorological indicators are seamlessly derived from climate reanalysis, satellite-based indicators have been combined from two satellite sensors. First, sensors onboard the Sentinel-3 platforms provide data used for operational near-real time use, but these data are only available since 2018. Second, data for previous years (since 2000) have been extracted from the MODIS archive. Data acquired by sensors with different spectral channels characteristics require cross-calibration and homogenization. In this study the calibration was rendered on the product level, i.e. for NDVI and LST. Alternative approach would be to cross-calibrate radiances measured by the MODIS and OLCI/SLSTR instruments (at the Level-1 product level), then to perform atmospheric and Rayleigh scattering corrections in order to derive homogeneous, crosscalibrated time series of the NDVI and LST products. This approach would significantly increase computational demand and complexity of the forecasting system which is not advisable for an operational system. Furthermore, within this study the cross-calibration at the Level-2 product level was found to significantly improve the homogeneity of data records (Table 2) and not to introduce significant variability which would influence the crop yield forecasting system (see Section 4.1).

\subsection{Heterogeneity of spectral signatures at the moderate spatial resolution}

Satellite-based predictors (i.e. NDVI, LST, VCI, TCI) used in the proposed crop yield forecasting system are not crop specific due to coarse spatial resolution of pixels $(\geq 300 \mathrm{~m})$ which may cover several agricultural fields sown with different plants. Nevertheless, such heterogeneous spectral signatures have been successfully used as a proxy for vegetation condition and consequently as a predictor of crop yields (e.g. [11]). Yet, the new generations of satellite sensors such as Multispectral Instrument (MSI) onboard Sentinel-2 satellite constellation acquire images at both high temporal ( $\sim 5$ days) and spatial $(\sim 10 \mathrm{~m})$ resolutions. This is a prerequisite to extract spectral signatures for individual fields and consequently to obtain a clear spectral signature related to physical characteristics of a particular crop [38]. Although the Sentinel-2 imagery is available, there are still some limitations that void its utilization within the crop yield forecasting systems. One of the limitations is the short Sentinel-2 data record (since 2015) which cannot be easily extended by means of cross-calibration with an older sensor (such as MODIS in this study) due to unavailability of such instrument featuring comparable spatial and temporal resolutions. Short time series hinders derivation of long-term anomalies and reduces the quality of crop yield forecast performed by a machine learning algorithm (Figure 15). Another limitation to the assimilation of high resolution satellite imagery to crop yield forecasts at a large/continental scale is lack of extensive multitemporal reference information on crop yields and crop types at an agricultural field level. Nevertheless these gaps are being quickly bridged by the expanding Sentinel-2 archive and by reference in-situ data on crop productivity collected by sensors mounted on novel agricultural equipment (e.g. harvesters). Consequently, several studies have already tackled the problem of crop yield forecasting based on high resolution Sentinel-2 imagery $[39,40]$. The future extensions of the proposed system will allow for crop yield predictions at a field level. However, to date it is not possible due to data availability and quality issues. Thus, the system we present is based on medium resolution satellite imagery which does not allow monitoring of individual fields. However, it should be emphasised that the forecasting system has been designed in such a way that changing the input data from Sentinel-3 to Sentinel-2 and switching to the clear spectral signature of specific crops requires only adaptation of the data input module. Then, it would be also possible to assimilate the Copernicus High Resolution 
Vegetation Phenology and Productivity product [41], which provides information on crop development and productivity at the 10-m scale.

\subsection{Limitation of agro-meteorological indicators}

The proposed crop yield forecasting system is based on two groups of data. One group contains predictors related to the crop growth conditions described by agrometeorological indicators. The other group consists of satellite-derived vegetation indices describing the instantaneous physical state of crops affected by the growing conditions. The fusion of both groups of predictors improves the quality of crop yield forecasts because they mutually diminish their deficiencies/limitations. In this respect, the agrometeorological data (either originating from climatological reanalysis or from interpolation of synoptic observations), have a resolution of a few kilometres, which may be sufficient to describe air temperature, insolation or average precipitation across a flat terrain. However, some extreme weather events such as hailstorms, heavy rain, strong winds or frosts will not be captured by a coarse agro-meteorological data. Therefore, it is necessary to use satellite-based predictors, which characterise vegetation state induced by these adverse weather events. At the same time, satellite vegetation indices have their own limitations. Firstly, in the case of medium resolution imagery pixels contain a mixture of different crop types. Secondly, the saturation of NDVI above a certain biomass level [42] can hamper sensitivity to higher crop yields. Thus the synergy between agro-meteorological and satellite predictors positively impacts the crop yield modelling.

\subsection{Applicability of the crop yield forecasting system to other areas}

The presented system contains a module for automatic training of yield forecasting models. It includes the step of removing the correlated features, forward feature selection and selection of the best prediction method. It requires only inclusion of predictors, i.e. agro-meteorological and satellite data, and reference statistics on crop yields for administrative units. Therefore, the model can be easily adapted to other regions featuring similar crop growth conditions. Otherwise, a problem may occur related to a double growing season, as computation of the GDD in the current system assumes one main crop per year.

\section{Conclusions}

This study presents a fully automated crop yield forecasting system operating at the administrative-unit scale based on predictors originating from open-access Sentinel-3 satellite data and ERA- 5 climate reanalysis. The system gathers satellite and agrometeorological products, performs preprocessing, calculates yield predictors, transforms them to thermal time (as a proxy for crop development stage), predicts crop yields and generates the final outputs (tabular, graphical). The prediction module runs exTreme Gradient Boosting regressor, which is preceded by the iterative predictor selection procedure. The system was intensively validated at NUTS-2 and LAU units in Poland for winter wheat, winter rapeseed and maize using leave-one-year-out procedure. The analysed period covered 2000-2019, however the availability of the reference data differed among administrative units. The performance (relative RMSE) of the end-ofseason forecasts for NUTS-2 was $8.15 \%$ for winter wheat, and around $13 \%$ for maize as well as for winter rapeseed. The system was designed in a way that it can be easily applied to other regions, where reference yields statistics are available, as well as it can be easily migrated to cloud computing environments (e.g. DIAS or Amazon AWS), where the Copernicus data sets are directly accessible.

Author Contributions: Conceptualization, J.B., S.S., J.M.; methodology, J.B., S.S., J.M.; software, J.B., S.S., J.M.; validation, J.B., S.S., P.S.; formal analysis, J.B., S.S.; investigation, J.B., S.S.; data curation, J.B., S.S., J.M.; writing-original draft preparation, J.B.; writing-review and editing, J.B., S.S., J.M, E.W., K.D.-Z., P.S., T.M, A.Ł.; visualization, J.B., S.S.; project administration, J.B., K.D.-Z., 
T.M, A.Ł.; funding acquisition, J.B., E.W., K.D.-Z., T.M, A.Ł. All authors have read and agreed to the published version of the manuscript.

Funding: This work was supported by the National Centre for Research and Development-Poland under grant agreement no. GOSPOSTRATEG1/381705/13/NCBR/2018, and by the European Space Agency under contract no. 4000123852/18/NL/CBi.

Conflicts of Interest: The authors declare no conflict of interest.

\section{References}

1. Becker-Reshef, I.; Justice, C.; Barker, B.; Humber, M.; Rembold, F.; Bonifacio, R.; Zappacosta, M.; Budde, M.; Magadzire, T.; Shitote, C.; Pound, J.; Constantino, A.; Nakalembe, C.; Mwangi, K.; Sobue, S.; Newby, T.; Whitcraft, A.; Jarvis, I.; Verdin, J. Strengthening agricultural decisions in countries at risk of food insecurity: The GEOGLAM Crop Monitor for Early Warning. Remote Sensing of Environment 2020, 237, 111553. doi:10.1016/j.rse.2019.111553.

2. Lobell, D.B.; Cassman, K.G.; Field, C.B. Crop yield gaps: their importance, magnitudes, and causes. Annual Review of Environment and Resources 2009, 34, 179-204. doi:10.1146/annurev.environ.041008.093740.

3. Lobell, D.B. The use of satellite data for crop yield gap analysis. Field Crops Research 2013, 143, 56-64. doi:10.1016/j.fcr.2012.08.008.

4. Mathew, I.; Shimelis, H.; Mutema, M.; Chaplot, V. What crop type for atmospheric carbon sequestration: Results from a global data analysis. Agriculture, Ecosystems \& Environment 2017, 243, 34-46. doi:10.1016/j.agee.2017.04.008.

5. Turkeltaub, T.; Kurtzman, D.; Russak, E.E.; Dahan, O. Impact of switching crop type on water and solute fluxes in deep vadose zone. Water Resources Research 2015, 51, 9828-9842. doi:10.1002/2015wr017612.

6. Gilbert, N. One-third of our greenhouse gas emissions come from agriculture. Nature 2012. doi:10.1038/nature.2012.11708.

7. Ray, D.K.; Gerber, J.S.; MacDonald, G.K.; West, P.C. Climate variation explains a third of global crop yield variability. Nature Communications 2015, 6. doi:10.1038/ncomms6989.

8. Iizumi, T.; Sakai, T. The global dataset of historical yields for major crops 1981-2016. Scientific Data 2020, 7. doi:10.1038/s41597020-0433-7.

9. Becker-Reshef, I.; Vermote, E.; Lindeman, M.; Justice, C. A generalized regression-based model for forecasting winter wheat yields in Kansas and Ukraine using MODIS data. Remote Sensing of Environment 2010, 114, 1312-1323. doi:10.1016/j.rse.2010.01.010.

10. Tucker, C.J.; Holben, B.N.; Elgin, J.H.; McMurtrey, J.E. Relationship of spectral data to grain yield variation. Photogrammetric Engineering and Remote Sensing 1980, 45, 600-608.

11. Dabrowska-Zielinska, K.; Kogan, F.; Ciolkosz, A.; Gruszczynska, M.; Kowalik, W. Modelling of crop growth conditions and crop yield in Poland using AVHRR-based indices. International Journal of Remote Sensing 2002, 23, 1109-1123. doi:10.1080/01431160110070744.

12. Bastiaanssen, W.G.M.; Ali, S. A new crop yield forecasting model based on satellite measurements applied across the Indus Basin, Pakistan. Agriculture, Ecosystems E Environment 2003, 94, 321-340. doi:10.1016/s0167-8809(02)00034-8.

13. Basnyat, P.; McConkey, B.; Lafond, G.P.; Moulin, A.; Pelcat, Y. Optimal time for remote sensing to relate to crop grain yield on the Canadian prairies. Canadian Journal of Plant Science 2004, 84, 97-103. doi:10.4141/p03-070.

14. Kogan, F.; Yang, B.; Wei, G.; Zhiyuan, P.; Xianfeng, J. Modelling corn production in China using AVHRR-based vegetation health indices. International Journal of Remote Sensing 2005, 26, 2325-2336. doi:10.1080/01431160500034235.

15. Prasad, A.K.; Chai, L.; Singh, R.P.; Kafatos, M. Crop yield estimation model for Iowa using remote sensing and surface parameters. International Journal of Applied Earth Observation and Geoinformation 2006, 8, 26-33. doi:10.1016/j.jag.2005.06.002.

16. Moriondo, M.; Maselli, F.; Bindi, M. A simple model of regional wheat yield based on NDVI data. European Journal of Agronomy 2007, 26, 266-274. doi:10.1016/j.eja.2006.10.007.

17. Kowalik, W.; Dabrowska-Zielinska, K.; Meroni, M.; Raczka, T.U.; de Wit, A. Yield estimation using SPOT-VEGETATION products: A case study of wheat in European countries. International Journal of Applied Earth Observation and Geoinformation 2014, 32, 228-239. doi:10.1016/j.jag.2014.03.011.

18. Johnson, D.M. An assessment of pre- and within-season remotely sensed variables for forecasting corn and soybean yields in the United States. Remote Sensing of Environment 2014, 141, 116-128. doi:10.1016/j.rse.2013.10.027.

19. Shao, Y.; Campbell, J.B.; Taff, G.N.; Zheng, B. An analysis of cropland mask choice and ancillary data for annual corn yield forecasting using MODIS data. International Journal of Applied Earth Observation and Geoinformation 2015, 38, 78-87. doi:10.1016/j.jag.2014.12.017.

20. Weiss, M.; Jacob, F.; Duveiller, G. Remote sensing for agricultural applications: A meta-review. Remote Sensing of Environment 2020, 236, 111402. doi:10.1016/j.rse.2019.111402.

21. Kussul, N.; Mykola, L.; Shelestov, A.; Skakun, S. Crop inventory at regional scale in Ukraine: developing in season and end of season crop maps with multi-temporal optical and SAR satellite imagery. European Journal of Remote Sensing 2018, 51, 627-636. doi:10.1080/22797254.2018.1454265.

22. Rao, P.; Zhou, W.; Bhattarai, N.; Srivastava, A.K.; Singh, B.; Poonia, S.; Lobell, D.B.; Jain, M. Using Sentinel-1, Sentinel-2, and Planet Imagery to Map Crop Type of Smallholder Farms. Remote Sensing 2021, 13, 1870. doi:10.3390/rs13101870.

23. Tricht, K.V.; Gobin, A.; Gilliams, S.; Piccard, I. Synergistic Use of Radar Sentinel-1 and Optical Sentinel-2 Imagery for Crop Mapping: A Case Study for Belgium. Remote Sensing 2018, 10, 1642. doi:10.3390/rs10101642. 
24. Franch, B.; Vermote, E.; Skakun, S.; Roger, J.; Becker-Reshef, I.; Murphy, E.; Justice, C. Remote sensing based yield monitoring: Application to winter wheat in United States and Ukraine. International Journal of Applied Earth Observation and Geoinformation 2019, 76, 112-127. doi:10.1016/j.jag.2018.11.012.

25. Lobell, D.B.; Asner, G.P.; Ortiz-Monasterio, J.I.; Benning, T.L. Remote sensing of regional crop production in the Yaqui Valley, Mexico: estimates and uncertainties. Agriculture, Ecosystems E Environment 2003, 94, 205-220. doi:10.1016/s0167-8809(02)00021-x.

26. Nolasco, M.; Ovando, G.; Sayago, S.; Magario, I.; Bocco, M. Estimating soybean yield using time series of anomalies in vegetation indices from MODIS. International Journal of Remote Sensing 2020, 42, 405-421. doi:10.1080/01431161.2020.1809736.

27. Doraiswamy, P. Crop condition and yield simulations using Landsat and MODIS. Remote Sensing of Environment 2004, 92, 548-559. doi:10.1016/j.rse.2004.05.017.

28. Schulzweida, U. CDO User Guide 2020. doi:10.5281/ZENODO.5614769.

29. Theil, H. A Rank-Invariant Method of Linear and Polynomial Regression Analysis. In Advanced Studies in Theoretical and Applied Econometrics; Springer Netherlands, 1992; pp. 345-381. doi:10.1007/978-94-011-2546-8_20.

30. Genovese, G.; Vignolles, C.; Nègre, T.; Passera, G. A methodology for a combined use of normalised difference vegetation index and CORINE land cover data for crop yield monitoring and forecasting. A case study on Spain. Agronomie 2001, 21,91-111. doi:10.1051/agro:2001111.

31. Bonhomme, R. Bases and limits to using 'degree.day' units. European Journal of Agronomy 2000, 13, 1-10. doi:10.1016/s11610301(00)00058-7.

32. Duveiller, G.; Baret, F.; Defourny, P. Using Thermal Time and Pixel Purity for Enhancing Biophysical Variable Time Series: An Interproduct Comparison. IEEE Transactions on Geoscience and Remote Sensing 2013, 51, 2119-2127. doi:10.1109/tgrs.2012.2226731.

33. Trudgill, D.L.; Honek, A.; Li, D.; Straalen, N.M. Thermal time - concepts and utility. Annals of Applied Biology 2005, 146, 1-14. doi:10.1111/j.1744-7348.2005.04088.x.

34. Kogan, F.N. Global Drought Watch from Space. Bulletin of the American Meteorological Society 1997, 78, 621-636. doi:10.1175/15200477(1997)078<0621:gdwfs >2.0.co;2.

35. Chen, T.; Guestrin, C. XGBoost: A scalable tree boosting system. Proceedings of the 22nd ACM SIGKDD International Conference on Knowledge Discovery and Data Mining. ACM, 2016. doi:10.1145/2939672.2939785.

36. Guyon, I.; Weston, J.; Barnhill, S.; Vapnik, V. Gene Selection for Cancer Classification using Support Vector Machines. Machine Learning 2002, 46, 389-422. doi:10.1023/a:1012487302797.

37. Kuśmierek-Tomaszewska, R.; Żarski, J. Assessment of Meteorological and Agricultural Drought Occurrence in Central Poland in 1961-2020 as an Element of the Climatic Risk to Crop Production. Agriculture 2021, 11, 855. doi:10.3390/agriculture11090855.

38. Veloso, A.; Mermoz, S.; Bouvet, A.; Toan, T.L.; Planells, M.; Dejoux, J.F.; Ceschia, E. Understanding the temporal behavior of crops using Sentinel-1 and Sentinel-2-like data for agricultural applications. Remote Sensing of Environment 2017, 199, 415-426. doi:10.1016/j.rse.2017.07.015.

39. Skakun, S.; Vermote, E.; Franch, B.; Roger, J.C.; Kussul, N.; Ju, J.; Masek, J. Winter Wheat Yield Assessment from Landsat 8 and Sentinel-2 Data: Incorporating Surface Reflectance, Through Phenological Fitting, into Regression Yield Models. Remote Sensing 2019, 11, 1768. doi:10.3390/rs11151768.

40. Franch, B.; Bautista, A.S.; Fita, D.; Rubio, C.; Tarrazó-Serrano, D.; Sánchez, A.; Skakun, S.; Vermote, E.; Becker-Reshef, I.; Uris, A. Within-Field Rice Yield Estimation Based on Sentinel-2 Satellite Data. Remote Sensing 2021, 13, 4095. doi:10.3390/rs13204095.

41. Tian, F.; Cai, Z.; Jin, H.; Hufkens, K.; Scheifinger, H.; Tagesson, T.; Smets, B.; Hoolst, R.V.; Bonte, K.; Ivits, E.; Tong, X.; Ardö, J.; Eklundh, L. Calibrating vegetation phenology from Sentinel-2 using eddy covariance, PhenoCam, and PEP725 networks across Europe. Remote Sensing of Environment 2021, 260, 112456. doi:10.1016/j.rse.2021.112456.

42. Gamon, J.A.; Field, C.B.; Goulden, M.L.; Griffin, K.L.; Hartley, A.E.; Joel, G.; Penuelas, J.; Valentini, R. Relationships Between NDVI, Canopy Structure, and Photosynthesis in Three Californian Vegetation Types. Ecological Applications 1995, 5, $28-41$. doi:10.2307/1942049. 